\title{
Decreased expression of ING2 gene and its clinicopathological significance in Chinese NSCLC patients
}

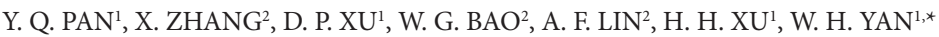 \\ ${ }^{1}$ Medical Research Center, Taizhou Hospital of Zhejiang Province, Wenzhou Medical College, Linhai, Zhejiang, China; ${ }^{2}$ Human Tissue Bank, \\ Taizhou Hospital of Zhejiang Province, Wenzhou Medical College, Linhai, Zhejiang, China
}

${ }^{*}$ Correspondence: yanwhcom@yahoo.com

Received September 19, 2013 / Accepted January 8, 2014

\begin{abstract}
The inhibitor of growth 2 (ING2) is a member of ING family, involved in cell cycle regulation, DNA repair, apoptosis and senescence, and participating in chromatin remodeling and transcriptional regulation by histone modification. Recent researches suggest ING2 plays roles in carcinogenesis both as tumor suppressor gene and ongocene depending on tumor types and cell status. Here, we investigated the status of ING2 in a series of 64 Chinese non-small cell lung cancer (NSCLC) patients using immunohistochemistry (IHC) and confirmed the results with Western blotting. RT-PCR results revealed the expression level of ING2 was consistent with mRNA level. The IHC results showed that ING2 protein expression was significantly decreased in NSCLC samples compared with normal lung tissues $(P<0.05)$. ING2 expression was lost in $32.8 \%$ $(21 / 64)$ NSCLC tissues, which was more frequently in adenocarcinoma (ADK) than in squamous cell carcinoma (SCC), $45.8 \%$ $(11 / 24)$ and $26.3 \%$ (10/38), respectively. We also found ING2 translocation from the nucleus to the cytoplasm, which may be a critical event for carcinogenesis. And the status of ING2 in SCC was significantly associated with lymph node metastasis status and TNM stage. After sequencing ING2 gene, we found no heterozygosity or mutation. Taken together, these results indicated that the aberrantly expression of ING2 may contribute to NSCLC tumorigenesis.
\end{abstract}

Key words: inhibitor of growth 2, non-small cell lung cancer, pathology

Lung cancer remains the leading cause of cancer-related deaths worldwide [1]. Early diagnosis with surgical resection has a $67 \% 5$-year survival [2]. However, the total 5-year survival rate of lung cancer cases was less than $17 \%$ [1], due to the lack of sensitive screening tests for early detection of lung cancer and ineffective treatment for advanced and metastatic disease [3]. Non-small-cell lung carcinoma (NSCLC) accounts for approximately $80 \%$ to $85 \%$ of all lung cancers. The development of NSCLC is a complex progress associated with multiple factors and stages, including accumulation of activation of oncogenes and inactivation of tumor suppressor genes [4]. Although several molecular predictors are being identified involving in lung tumorgenesis, others remain to be discovered [5]. Further researches on suppressor genes, apoptosis-related genes, and autophagy-related genes in the tumor progression of NSCLC will contribute to new strategies for early diagnosis, prognostic indictors and treatment of NSCLC [6].

The inhibitor of growth family member 2 (ING2) was identified as a candidate of tumor suppressor by computational homology search with ING1 in 1998, mapped to chromosome $4 \mathrm{q} 35.1$ and localized to the subtelomeric region of chromosome 4 [7]. ING2 is comprised of three exons, exon $1 \mathrm{a}, 1 \mathrm{~b}$ and 2 , which encodes two isoforms, ING2a and ING2b, resulting from an alternative splicing between exons $1 \mathrm{a}$ and $1 \mathrm{~b}$ [8]. The expression level of ING2b mRNA is much lower than ING2a, and ING2b protein has never been detected [9]. ING2a also called ING2 and ING1L, encodes a $33 \mathrm{kDa}$ protein shares the highest amino acid homology with ING1 among the ING protein family members (ING1 to ING5) [10]. ING2a protein is characterized by 6 highly conserved regions, including a leucine zipper-like (LZL) motif at the N-terminal end, a potential chromatin regulatory domain (PCR), a nuclear localization sequence (NLS) containing 3 nuclear targeting sequences (NTS), a phosphorylation-dependent interacting motif (PDIM), a plant homeodomain (PHD) zinc-finger in C-terminal region and a protein-interacting motif (PIM) [11]. ING2a promoter possesses regulatory elements such as two p53 binding sites and one NF- $\kappa B$ binding site that control its transcription. Moreover, 
ING2a protein expression level has reported to be regulated by ubiquitylation interacting with SMURF1 (Smad Ubiquitination Regulating Factor 1) [12]. ING2 has also been shown to interact with several other proteins such as $\mathrm{p} 300$, the $\mathrm{mSin} 3 \mathrm{~A}-\mathrm{HDAC}$ complex, the Brg-based SWI-SNF complex, BRMS1, trimethylated histone $\mathrm{H} 3$ lysine 4 (H3K4me3) and phosphatidylinositol 5-phosphate [10, 13-17]. These interactions are important for the functions of ING2 in cell cycle regulation, DNA repair, apoptosis, senescence, chromatin remodeling and transcriptional regulation [18]. ING2 proteins were mainly localized in the nucleus [17] and the expression of ING2 is relatively low in most normal tissues, except in testis [19]. High expression of ING2 was observed in testis and moderate expression was observed in ovary, skeletal muscle, and pancreas $[7,8]$.

The expression of ING genes is frequently lost or downregulated in human tumors [20]. Most studies on ING1 addressed a significant decrease or loss of ING1 at mRNA and protein level, including lung cancer [21]. Although ING2 has been considered to be a candidate tumor suppressor gene for more than a decade, recent evidences suggest it also play roles as a tumor oncogene [22]. Since the complicated roles of ING2 played in various types of cancers, we investigated the expression of ING2 protein in Chinese NSCLC patients by immunohistochemistry and Western blotting, and then analyzed the associations between the protein expression status of ING2 and clinico-pathological features.

\section{Materials and methods}

Patients and tissue specimens. NSCLC tumor lesions were obtained from 64 Chinese patients ( 48 men and 16 women, age range from 45 to 76 years with a median age of 57.5 years) who were diagnosed and treated consecutively in Taizhou Hospital of Zhejiang Province affiliated to Wenzhou Medical College between January 2005 and August 2010. They consisted of 24 adenocarcinoma (ADK), 38 squamous cell carcinoma (SCC) and 2 adenosquamous carcinoma (ASC). And 28 cases of paired adjacent normal tissue specimens were also included. The adjacent normal tissues were from outside the margin of the tumors ( $>3 \mathrm{~cm}$ from border of the tumor), and had no caner cell invasion as demonstrated by hematoxylin and eosin (H\&E) staining. Tissue samples were taken at the time of surgical resection of lung cancer and were immediately frozen in liquid nitrogen and stored at $-80^{\circ} \mathrm{C}$ until use. Histological diagnosis and tumor grade were determined in accordance with the World Health Organization International Histological Classification of Lung Tumors criteria. Patients' data collected included age, gender, histological diagnosis, differentiation, size, lymph node metastasis, location and TNM stage. This study was performed following an Institutional Ethics Review Board approved protocol to investigate molecular markers relevant to lung cancer pathogenesis and informed consent was signed by all patients.

Immunohistochemistry. Sections $(4 \mu \mathrm{m})$ of the paraffin-embedded tissue blocks were cut and mounted on polylysine coated slides. Then they were dewaxed in xylene and re-hydrated in graded ethanols. After deparaffinization, antigen retrieval treatment was performed at $120^{\circ} \mathrm{C}$ (autoclave) for $5 \mathrm{~min}$ in a $10 \mathrm{nmol} / \mathrm{L}$ sodium citrate buffer ( $\mathrm{pH}$ 6.0). After inhibition of endogenous peroxidase activity using a $0.3 \%$ hydrogen peroxide solution at room temperature for $15 \mathrm{~min}$, sections were incubated with antiING2 poly (Sigma-Aldrich, USA, 1:90) overnight at $4^{\circ} \mathrm{C}$. Binding sites of the primary antibody were visualized using a Dako EnVison kit (Dako, Glostrup, Denmark) in accordance with the manufacturer's instructions. Finally, sections were counterstained with hematoxylin and mounted with glycerol gelatin.

ING2 staining in NSCLC tissues was determined by two pathologists. The pathologists were blinded to any clinical details related to the patients. Percentage of ING2+ cells was determined by each observer, and the average of three scores was calculated. Normal testis tissues used as ING2 positive control and tissue sections immunoreacted without antiING2 antibody under the same experimental conditions as negative control. Evaluation of the ING2 expression level was classified into four groups: -, 0\%; +, 1-25\%; ++, 25-50\% and ,$+++>50 \%$, respectively. The percentage of positive cells was assigned a value based on the presence or absence of ING2 staining, irrespective of staining intensity. The group - labeled as negative, the other groups labeled as positive.

Western blot analysis. ING2 expression in part of these NSCLC samples was confirmed by Western blot with 10 casematched fresh lesions. After homogenized in nitrogen liquid, $100 \mathrm{mg}$ tissues were weighted and treated with $400 \mu \mathrm{l}$ lysis buffer ( $\mathrm{pH} 7.4,150 \mathrm{mM} \mathrm{NaCl}, 1 \mathrm{mM}$ ethylenediamineteraacetic acid, $1 \%$ Triton X-100, PMSF $1 \mathrm{mM}$ ), and then centrifugation at $12,000 \mathrm{~g}$ at $4^{\circ} \mathrm{C}$ for $30 \mathrm{~min}$ after homogenized with ultrasonic. Cell lysate aliquots were separated in 10\% SDS-PAGE gel and then electro-blotted onto PVDF membranes (Millipore, Bedford, MA, USA) and blocked by incubating with PBS containing $5 \%$ non-fat dry milk for $4 \mathrm{hrs}$. After blocking, membranes were washed in PBS containing $0.2 \%$ Tween- 20 for three times and then probed with the primary polyclonal antibody against ING2 (Sigma-Aldrich, USA) at 1:250 dilution, and $\beta$-actin (Sigma-Aldrich, USA) at 1:2000 dilution overnight at $4^{\circ} \mathrm{C}$. After incubation, membranes were washed in PBS containing $0.2 \%$ Tween-20 for another three times. The membranes were subsequently incubated for $30 \mathrm{~min}$ at room temperature with Peroxidase/DAB+ Rabbit/Mouse (Dako), and developed with Dako REAL ${ }^{\mathrm{TM}}$ EnVision $^{\mathrm{TM}}$ Detection System (Dako) for 1-3min. The density of ING2 concentration was determined with Quant one analysis image software (Bio-Rad, USA) and normalized with $\beta$-actin.

RNA isolation and RT-PCR. Total RNA was extracted using TrizolReagent (Invitrogen, Carlsbad, CA, USA) according to the manufacturer's protocol. RNA concentration and quantity were assessed by absorbency at 260nm using a DNA/Protein Analyzer (Eppendorf, Germany). $2 \mu \mathrm{g}$ of total RNA was reverse transcribed into first-stand cDNA with Moloney murine leukemia virus reverse transcriptase (Invitrogen, NY, USA) and oligo(dT) 12-18 primers (Invitrogen, NY, USA) in a 20 $\mu$ l reaction. Subsequently, PCR amplification was performed on 500ng 


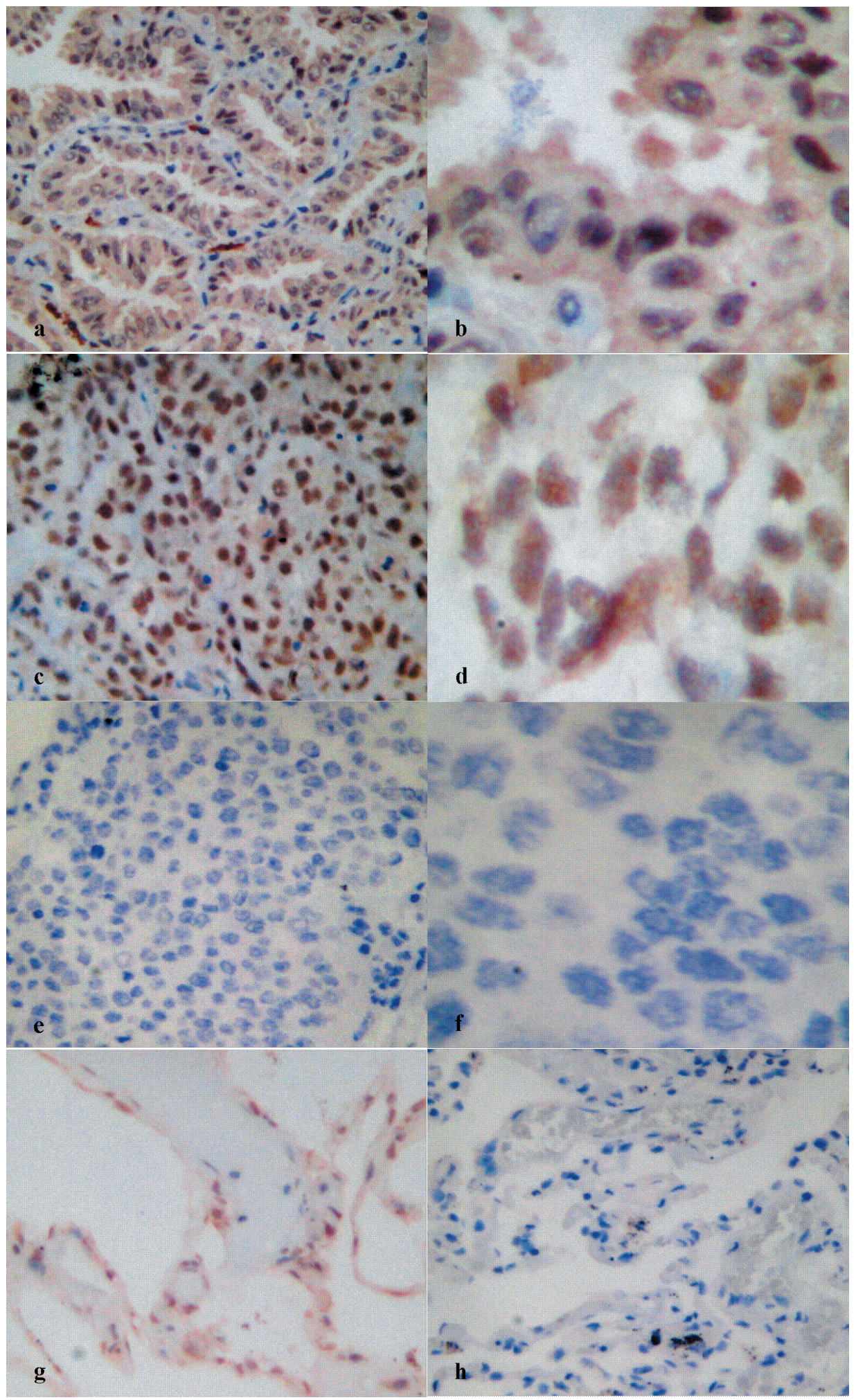

Figure 1. Immunohistochemical staining of NSCLC tissue lesions and surrounding non-cancerous tissues use an anti-ING2 antibody. (a and b) Positive staining with both cytoplasm and nuclear in NSCLC lesions at two different magnification $(100 \times)$ and $(400 \times)$, respectively. (c and d) Positive staining with nuclear in NSCLC lesions at two different magnification $(100 \times)$ and $(400 \times)$, respectively. (e and f) Negative staining of NSCLC lesions at two different magnification $(100 \times)$ and $(400 \times)$, respectively. (g) Positive staining of surrounding non-cancerous tissues (100x). (h) Negative staining of surrounding non-cancerous tissues $(100 \times)$. 
cDNA template with the following condition: $2.5 \mu \mathrm{l} 10 \times \mathrm{PCR}$ buffer, $0.5 \mu 110 \mathrm{mM} 2$ '-deoxyribonucleotide 5'-triphosphate (dNTP) mix, 20pmol of each primer, $1.5 \mathrm{mM} \mathrm{MgCl}_{2}$, and $0.5 \mathrm{U}$ Taq polymerase (Roche, Indianapolis, USA) in a final volume of $25 \mu$ l. RT-PCR was performed with GAPDH as an internal control. The primers used were listed as follows: ING2 (sense: 5'-AAC GAG CCT CAG ATA AAG CA-3', antisense: 5'-GAT CAT CAC AGT CTT CAA TCC C-3'), GAPDH (sense: 5'-GAA ATC CCA TCA CCA TCT TCC AGG-3', antisense: 5'-GAG CCC CAG CCT TCT CCA TG-3'), and the corresponding PCR products are $132 \mathrm{bp}$ and $120 \mathrm{bp}$, respectively. PCR amplification was programmed for 1 cycle at $95^{\circ} \mathrm{C}$ for $4 \mathrm{~min}, 30$ cycles of $95^{\circ} \mathrm{C}$ for $30 \mathrm{~s}, 58^{\circ} \mathrm{C}$ for $45 \mathrm{~s}$ and $72^{\circ} \mathrm{C}$ for $30 \mathrm{~s}$, followed by a final extension of $7 \mathrm{~min}$ at $72^{\circ} \mathrm{C}$. The amplification products were electrophoresed through $1.5 \%(\mathrm{w} / \mathrm{v})$ low melting point (LMP) agarose gels and visualized with ethidium bromide (Sigma, St. Louis, MO, USA) on top of a UV light illuminator. The density of ING2 concentration was performed using Quant one analysis image software and normalized with GAPDH.

Genomic DNA extraction and sequencing. Genomic DNA from frozen tumors and normal lung tissues samples were digested with proteinase $\mathrm{K}$ and extracted using the DNeasy Blood \& Tissue kit (Qiagen, Hilden, Germany) according to the manufacture's recommendations. The primers specific for ING2 exon1 were: sense 5'-CGG ATC GGC AGG ATG TTA GG-3' and anti-sense 5'- TGT CAC GGG AGA AAG GGA AG-3', while for ING2 exon2 were: sense 5'- TGA GTT CTA ATT TCA ATT CTG T- 3' and antisense 5'-TTA CCC TAA AAC ATT TTC TGA-3', respectively. PCR products were purified and cycle sequencing was performed using BigDye Terminator v3.1 (Applied Biosystems, Foster City, CA).

Statistical analysis. All statistical analyses were performed with SPSS 13.0 software (SPSS, Inc., Chicago, IL). Differences in ING2 expression between NSCLC tissues and adjacent tissues were analyzed by non-parametric Mann-Whitney $U$ test. Correlations between the ING2 expression status and clinical parameters were calculated with Pearson chi-square test. $P$ values $<0.05$ was considered statistically significant.

\section{Results}

ING2 expression in NSCLC and adjacent normal tissues. The clinicopathological features of 64 cases of NSCLC were summarized in Table 1. To investigate whether ING2 protein was dysregulated in NSCLC, the expression of ING2 in NSCLC $(n=64)$ and paired adjacent non-tumor tissues $(n=28)$ were analyzed in this study. The expression level of ING2 was valued as the way described in the section of immunohistochemistry. The expression of ING2 protein was located both in the cytoplasm and nucleus in several NSCLC tissues. However, in the non-tumor tissues, ING2 expression was mostly staining in the nucleus (Fig.1). The expression of ING2 was significantly decreased in NSCLC when compared with the adjacent nontumor tissues $(P<0.05)$ (Fig.2).

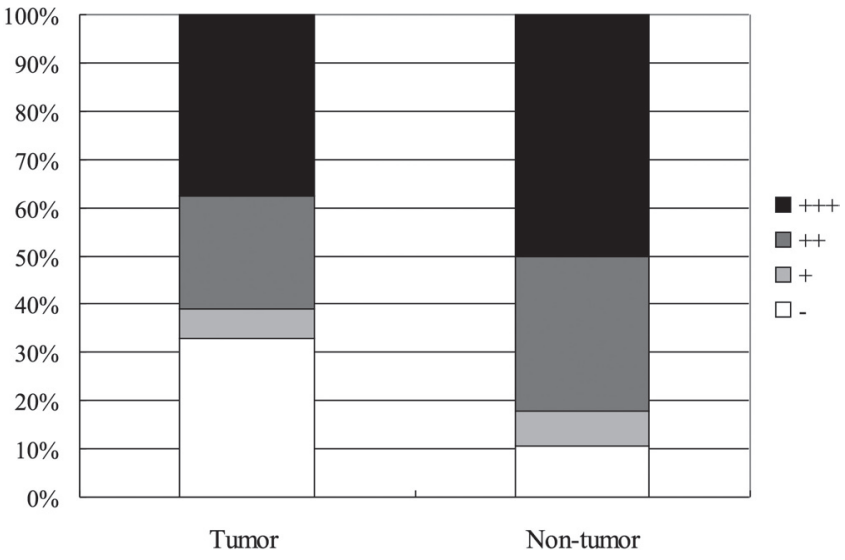

Figure 2. Summary results of ING2 protein staining in NSCLC and their matched non-malignant lung tissues with IHC $(n=28)$. The levels of staining for ING2 expression were significantly decreased in NSCLC compared with non-tumor lung tissues $(P<0.05)$.

Table 1. Correlations between ING2 expression and clinicopathologic parameters of 64 NSCLC cases

\begin{tabular}{|c|c|c|c|c|c|}
\hline \multirow[b]{2}{*}{ Variable } & \multicolumn{2}{|c|}{$\begin{array}{l}\text { Cases in } \\
\text { each group }\end{array}$} & \multicolumn{2}{|c|}{ ING2 expression } & \multirow[b]{2}{*}{$\mathrm{p}$-Value } \\
\hline & $\mathrm{n}$ & $\%$ & Negative & Positive & \\
\hline Age & & & & & 0.247 \\
\hline$\leq 57.5$ & 33 & 51.6 & 13 & 20 & \\
\hline$>57.5$ & 31 & 48.4 & 8 & 23 & \\
\hline Gender & & & & & 0.192 \\
\hline Male & 49 & 76.6 & 14 & 35 & \\
\hline Female & 15 & 23.4 & 7 & 8 & \\
\hline NSCLC subtype & & & & & 0.114 \\
\hline $\mathrm{ADK}$ & 24 & 37.5 & 11 & 13 & \\
\hline SCC & 38 & 59.4 & 10 & 28 & \\
\hline Differentiation & & & & & 0.750 \\
\hline Poor and undifferantiated & 17 & 30.9 & 4 & 13 & \\
\hline Well and moderate & 38 & 69.1 & 12 & 26 & \\
\hline Size & & & & & 0.365 \\
\hline$\leq 5 \mathrm{~cm}$ & 34 & 61.8 & 9 & 25 & \\
\hline$>5 \mathrm{~cm}$ & 21 & 38.2 & 8 & 13 & \\
\hline Lymph node metastasis & & & & & 0.653 \\
\hline Without & 30 & 46.9 & 9 & 21 & \\
\hline With & 34 & 53.1 & 12 & 22 & \\
\hline Tumor location & & & & & 0.179 \\
\hline Left & 29 & 45.3 & 7 & 22 & \\
\hline Right & 35 & 54.7 & 14 & 21 & \\
\hline TNM stage & & & & & 0.232 \\
\hline I & 17 & 26.6 & 3 & 14 & \\
\hline II & 34 & 53.1 & 12 & 22 & \\
\hline III/IV & 13 & 20.3 & 6 & 7 & \\
\hline
\end{tabular}

${ }^{a}$ Comparison of ING2 expression status between or among each variable using the Pearson chi-square test. 
To further investigate if the expression of ING2 is decreased at protein level in NSCLC, we performed Western blot on NSCLC specimens and corresponding adjacent non-cancerous lung tissues $(\mathrm{n}=10)$. To determine the mechanisms by which ING2 decrease of expression occurs in lung tumors, we investigate the
mRNA expression level of paired samples by semiquantitative RT-PCR and the possibility of the mutation occurs in DNA sequences. Our data showed that immunohistochemistry results were highly consistent with that of the Western blot analysis and RT-PCR analysis (Fig.3A, B and C), and ING2 protein expres-

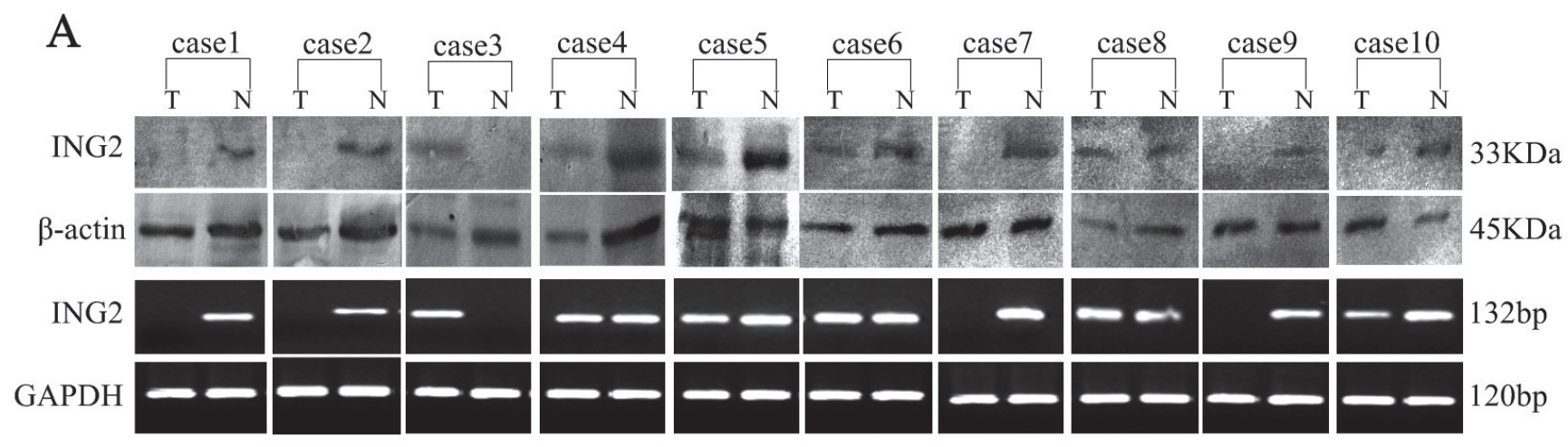

B

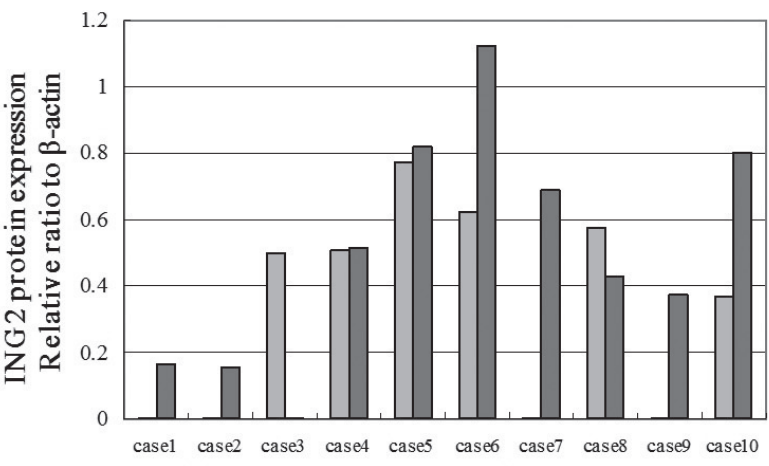

C

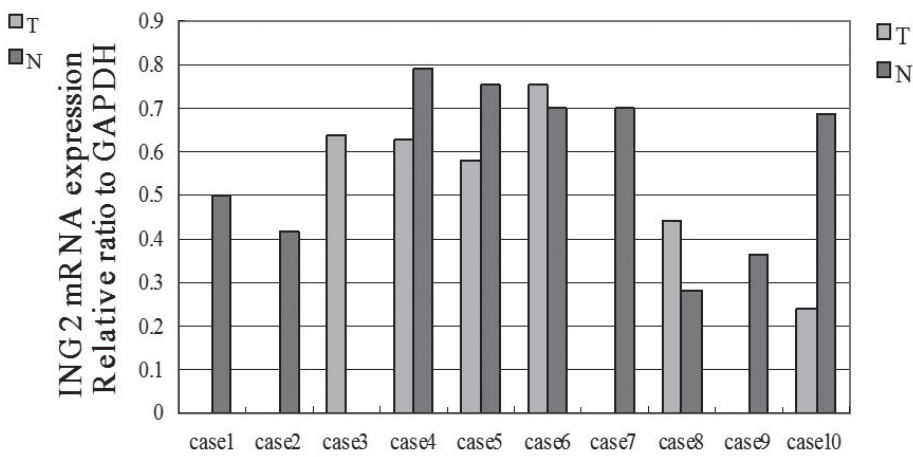

D

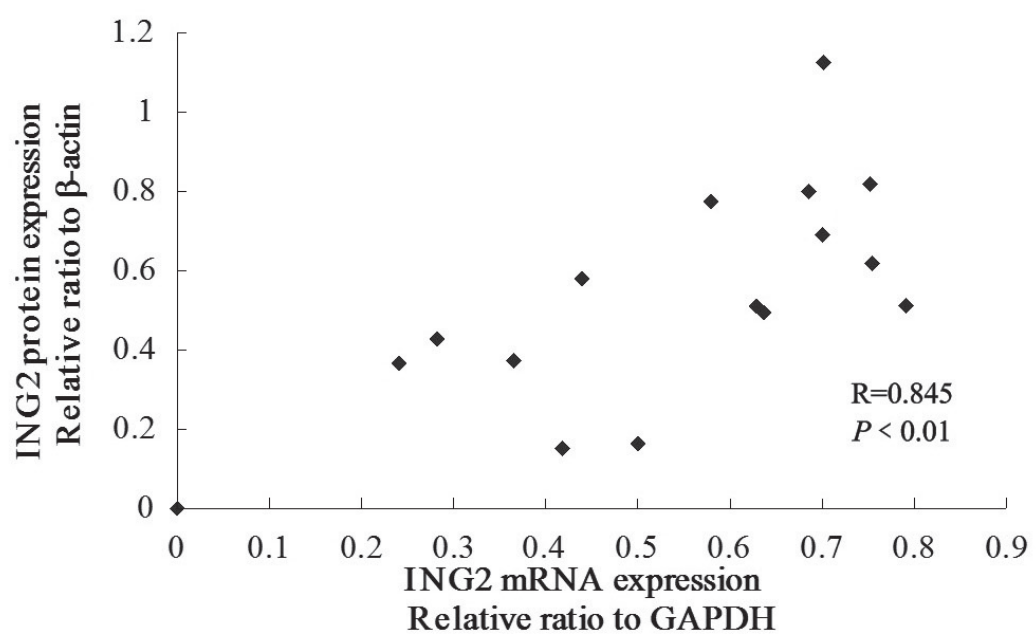

Figure 3. Expression pattern of ING2 in NSCLC and corresponding non-tumors specimens. (A, B and C) ING2 protein expression and mRNA expression in NSCLC and matched adjacent non-malignant tissues were examined using Western bolt with $\beta$-actin as loading control and RT-PCR with GAPDH as internal control respectively $(n=10)$. (D) ING2 protein expression was correlated with ING2 mRNA expression. Person's correlation analysis was performed $(\mathrm{R}=0.845, P<0.01)$. $\mathrm{T}$ : Tumor tissue, $\mathrm{N}$ : Non-tumor tissue. 
sion was positively correlated with the ING2 mRNA (Fig.3D, $P<0.01$ ). Mutation analysis of ING2 was performed in genomic DNA from 10 patients with NSCLC by PCR-direct sequencing and no mutation was identified in these cases.

Relationship between ING2 protein expression and clincopathological characters of NSCLC. ING2 expression was lost in $32.8 \%$ (21/64) NSCLC tissues, which was more frequently in ADK, $45.8 \%$ (11/24), than in SCC, $26.3 \%$ (10/38). ING2 expression in NSCLC lesions was not significantly associated with clinical parameters such as patient age, gender, tumor subtype, differentiation, size, lymph node metastasis location and TNM stage (Table 1).

However, considering the different proportions of ING2 loss in two subtypes of NSCLC, ADK and SCC, we analyzed the relationships between expression status of ING2 and ADK or SCC. ING2 expression in SCC lesions was associated with lymph node metastasis status ( $\chi^{2}$-test, $\left.P=0.008\right)$ and TNM stage ( $\chi^{2}$-test, $\left.P=0.036\right)$. However, ING2 expression in ADK and SCC was not significantly associated with other clinical parameters (Table 2).

\section{Discussion}

ING2, a member of ING family, has important functions in senescence, apoptosis, gene transcription, chromatin modification and DNA damage repair [23]. Previous studies also indicated that ING2 could interact with the transforming growth factor (TGF)- $\beta$ signaling pathways and enhance the transcription of target genes and cell cycle arrest [24].

A few studies have focused on the relationship between human ING2 and cancers. Two studies on basal cell carcinomas [25] and head and neck squamous cell carcinoma [26] revealed a $\mathrm{LOH}$ in the region of $4 \mathrm{q} 35$, which includes ING2, underlying a potential role of ING2 in both carcinomas. Other studies provided further evidence that ING2 was involved in tumorigenesis. Two studies by Okano [27] and Ythier D [28] described the reduced expression of ING2 in lung cancer cell lines and NSCLC respectively. In another study by Lu F [29], a reduced nuclear expression of ING2 was observed in human melanomas when compared to dysplastic nevi, while no correlation between ING2 nuclear expression and tumor growth phase or tumor stage was established. This data indicated that the reduced ING2 expression may involved in the initiation rather than progression of melanoma. The study of Zhang $\mathrm{H} \mathrm{K}$ [30] revealed that the lost of ING2 expression in hepatocellular carcinoma (HCC) could be involved in the progression of HCC and associated with poor prognosis. More recently, a study from Larrieu found a novel and specific function of ING2 in regulation of G1/S transition. ING2 may regulate G1/S transition by mediating $\mathrm{H} 3 \mathrm{~K} 4 \mathrm{me} 3$ at $\mathrm{p} 21$ promoter without p53 [31, 32]. This study revealed the knockdown of ING2 may accelerate cell cycle progression, which provides evidence for the potential link between loss of ING2 and cancer development. Another report by Saito M provides an animal model to study idiopathic and iatrogenic infertility in
Table 2. Correlations between ING2 expression and clinicopathologic parameters of 24 ADK cases and 38 SCC cases

\begin{tabular}{|c|c|c|c|c|c|}
\hline \multirow[b]{2}{*}{ Variable } & \multicolumn{2}{|c|}{$\begin{array}{c}\text { Cases in } \\
\text { each group }\end{array}$} & \multicolumn{2}{|c|}{ ING2 expression } & \multirow[b]{2}{*}{$\mathrm{p}$-Value $\mathrm{a}^{\mathrm{a}}$} \\
\hline & $\mathrm{n}$ & $\%$ & Negative & Positive & \\
\hline ADK Age & & & & & 0.217 \\
\hline$\leq 57.5$ & 11 & 45.8 & 7 & 4 & \\
\hline$>57.5$ & 13 & 54.2 & 4 & 9 & \\
\hline SCC Age & & & & & 1.000 \\
\hline$\leq 57.5$ & 21 & 55.3 & 6 & 15 & \\
\hline$>57.5$ & 17 & 44.7 & 4 & 13 & \\
\hline ADK Gender & & & & & 1.000 \\
\hline Male & 13 & 54.2 & 6 & 7 & \\
\hline Female & 11 & 45.8 & 5 & 6 & \\
\hline SCC Gender & & & & & 0.164 \\
\hline Male & 35 & 92.1 & 8 & 27 & \\
\hline Female & 3 & 7.9 & 2 & 1 & \\
\hline ADK Differentiation & & & & & 0.509 \\
\hline Poor and undifferantiated & 2 & 10.5 & 0 & 2 & \\
\hline Well and moderate & 17 & 89.5 & 7 & 10 & \\
\hline SCC Differentiation & & & & & 1.000 \\
\hline Poor and undifferantiated & 14 & 40.0 & 4 & 10 & \\
\hline Well and moderate & 21 & 60.0 & 5 & 16 & \\
\hline ADK Size & & & & & 0.214 \\
\hline$\leq 5 \mathrm{~cm}$ & 14 & 60.9 & 5 & 9 & \\
\hline$>5 \mathrm{~cm}$ & 9 & 39.1 & 6 & 3 & \\
\hline SCC Size & & & & & 1.000 \\
\hline$\leq 5 \mathrm{~cm}$ & 18 & 60 & 4 & 14 & \\
\hline$>5 \mathrm{~cm}$ & 12 & 30 & 2 & 10 & \\
\hline ADK Lymph node metastasis & & & & & 0.105 \\
\hline Without & 15 & 62.5 & 9 & 6 & \\
\hline With & 9 & 37.5 & 2 & 7 & \\
\hline SCC Lymph node metastasis & & & & & 0.008 \\
\hline Without & 13 & 34.2 & 0 & 13 & \\
\hline With & 25 & 65.8 & 10 & 15 & \\
\hline ADK Tumor location & & & & & 1.000 \\
\hline Left & 6 & 25.0 & 3 & 3 & \\
\hline Right & 18 & 75.0 & 8 & 10 & \\
\hline SCC Tumor location & & & & & 0.267 \\
\hline Left & 22 & 57.9 & 4 & 18 & \\
\hline Right & 16 & 42.1 & 6 & 10 & \\
\hline ADK TNM stage & & & & & 0.596 \\
\hline I-II & 20 & 83.3 & 10 & 10 & \\
\hline III-IV & 4 & 16.7 & 1 & 3 & \\
\hline SCC TNM stage & & & & & 0.036 \\
\hline I-II & 29 & 76.3 & 5 & 24 & \\
\hline III-IV & 9 & 23.7 & 5 & 4 & \\
\hline
\end{tabular}

a Comparison of ING2 expression status between or among each variable using the Pearson chi-square test.

men found the function of ING2 in spermatogenesis and also demonstrated an evidence of ING2 as a tumor suppressor by increased incidence of soft-tissue sarcomas in Ing2-/- mice [33]. Interestingly, a research on colon cancer suggest ING2 
also play roles as a tumor oncogene, which demonstrated ING2 was upregulated and increased invasion by enhanced MMP-13 [22]. In addition, a putative NF- $\kappa B$ binding site was found in the promoter of ING2 and the activation of NF- $\kappa B$ could positively regulate ING2 expression.

To our knowledge, there are no reports of ING2 in human NSCLC of Chinese population. In our study, we investigated the expression pattern of ING2 in Chinese NSCLC patients to evaluate its potential clinical relevance. Our findings demonstrate the expression of ING2 protein was significantly downregulated in NSCLC compared with paired normal lung tissues and the lost frequency of ADK was more than SCC, which is in accordance with the observations of Ythier D [34]. In our study ING2 expression was lost in 32.8\% NSCLC tissues. However, Ythier D reported ING2 was lost in more than 50\% NSCLC tissues. According to the results of Western blot and RT-PCR, we found that the dysregulation of ING2 in NSCLC occurred in both transcription and translation. Furthermore, in IHC results we investigated if the ING2 expression was translocated from nucleus to cytoplasm in several NSCLC tissues, especially in ING2 high staining samples, in contrast to normal tissues. In agreement with our results, the aberrantly localization of ING2 was also reported in some other tumors, including HCC [35] and colon cancer [22]. Moreover, study on ING1 and ING3, homologs of ING2, also found similar event in brain tumor [36] and HCC [37]. So we presumed that the mislocalization of ING2 may trigger the degradation and loss of its function in nucleus, which is similar to the lost of ING2 expression in NSCLC. The precise mechanism of the aberrantly localization of ING2 remains elusive and needs further research.

In the correlation analysis of ING2 and clinical characteristics, we found no relationship between ING2 staining and any variable in NSCLC. However, we found that ING2 expression in SCC lesions was negatively associated with lymph node metastasis status and TNM stage, which was not found in Ythier D's study. These findings demonstrated that the downregulation of ING2 may play a continued role in the processing of SCC advancement and development.

In addition, the sequencing data for ING2 exon1 and exon2 in this study showed that different expression levels of ING2 in NSCLC tissues was not relevant with loss of heterozygosity or mutations in ING2 DNA. This result is also in accordance with the observations of Okano, that no mutation was detected in 31 cancer cell lines and 30 lung cancer biopsies [27], and Ythier D, that no $\mathrm{LOH}$ and no sense mutation was found in lung cancer samples [34]. The ING2 involvement in tumors seems to be linked to the expression level rather than its mutation status [38].

Conclusively, our research suggested that the dysregulation of ING2 frequently occurred in NSCLC, including downregulation, lost expression and aberrantly localization, which may be related with the progression of NSCLC, particularly in SCC. Dysregulation of ING2 in NSCLC occurred in both transcription and translation levels, and it is a candidate of tumor suppressor gene for NSCLC.
More studies, especially on the role of the molecular mechanism of ING2 in carcinogenesis for NSCLC and other tumors, including cellular localization, crosstalk of ING2 with other ING family members need to be elucidated, which will help a better characterization of ING2 diagnostic and therapeutic potential for NSCLC and other tumors.

Acknowledgements: This study was supported by a grant from Natural Science Foundation of Zhejiang Province, China (Y205531, Y205575), the Science and Technology Bureau of Taizhou, Zhejiang Province, China (091KY04).

\section{References}

[1] SIEGEL R, NAISHADHAM D, JEMAL A. Cancer statistics, 2013. CA Cancer J Clin 2013; 63: 11-30. http://dx.doi. org/10.3322/caac. 21166

[2] GHOSAL R, KLOER P, LEWIS KE. A review of novel biological tools used in screening for the early detection of lung cancer. Postgrad Med J 2009; 85: 358-363. http://dx.doi. org/10.1136/pgmj.2008.076307

[3] DHILLON SS, LOEWEN G, JAYAPRAKASH V, REID ME. Lung cancer screening update. J Carcinog 2013; 12: 2. http:// dx.doi.org/10.4103/1477-3163.106681

[4] GOMPERTS BN, SPIRA A, MASSION PP, WALSER TC, WISTUBA II, et al. Evolving concepts in lung carcinogenesis. Semin Respir Crit Care Med 2011; 32: 32-43. http://dx.doi. org/10.1055/s-0031-1272867

[5] LIN J, BEER DG. Molecular predictors of prognosis in lung cancer. Ann Surg Oncol 2012; 19: 669-676. http://dx.doi. org/10.1245/s10434-011-1967-x

[6] LIU J, LIN Y, YANG H, DENG Q, CHEN G, et al. The expression of p33(ING1), p53, and autophagy-related gene Beclin1 in patients with non-small cell lung cancer. Tumour Biol 2011; 32: 1113-1121. http://dx.doi.org/10.1007/s13277-011-0211-4

[7] SHIMADA Y, SAITO A, SUZUKI M, TAKAHASHI E, HORIE M. Cloning of a novel gene (ING1L) homologous to ING1, a candidate tumor suppressor. Cytogenet Cell Genet 1998; 83: 232-235. http://dx.doi.org/10.1159/000015188

[8] UNOKI M, KUMAMOTO K, ROBLES AI, SHEN JC, ZHENG ZM, et al. A novel ING2 isoform, ING2b, synergizes with ING2a to prevent cell cycle arrest and apoptosis. Febs Lett 2008; 582: 3868-3874. http://dx.doi.org/10.1016/ j.febslet.2008.10.024

[9] GUERILLON C, LARRIEU D, PEDEUX R. ING1 and ING2: multifaceted tumor suppressor genes. Cell Mol Life Sci 2013. http://dx.doi.org/10.1007/s00018-013-1270-Z

[10] DOYON Y, CAYROU C, ULLAH M, LANDRY AJ, COTE V, et al. ING tumor suppressor proteins are critical regulators of chromatin acetylation required for genome expression and perpetuation. Mol Cell 2006; 21: 51-64. http://dx.doi. org/10.1016/j.molcel.2005.12.007

[11] COLES AH, JONES SN. The ING gene family in the regulation of cell growth and tumorigenesis. J Cell Physiol 2009; 218: 45-57. http://dx.doi.org/10.1002/jcp.21583

[12] KWEI KA, SHAIN AH, BAIR R, MONTGOMERY K, KARIKARI CA, et al. SMURF1 amplification promotes invasiveness 
in pancreatic cancer. PLoS One 2011; 6: e23924. http://dx.doi. org/10.1371/journal.pone.0023924

[13] GOEMAN F, OTTO K, KYRYLENKO S, SCHMIDT O, BANIAHMAD A. ING2 recruits histone methyltransferase activity with methylation site specificity distinct from histone $\mathrm{H} 3$ lysines 4 and 9. Biochim Biophys Acta 2008; 1783: 1673-1680. http://dx.doi.org/10.1016/j.bbamcr.2008.04.019

[14] PENA PV, HOM RA, HUNG T, LIN H, KUO AJ, et al. Histone $\mathrm{H} 3 \mathrm{~K} 4 \mathrm{me} 3$ binding is required for the DNA repair and apoptotic activities of ING1 tumor suppressor. J Mol Biol 2008; 380: 303-312. http://dx.doi.org/10.1016/j.jmb.2008.04.061

[15] SHI X, HONG T, WALTER KL, EWALT M, MICHISHITA E, et al. ING2 PHD domain links histone H3 lysine 4 methylation to active gene repression. Nature 2006; 442: 96-99.

[16] PEDEUX R, SENGUPTA S, SHEN JC, DEMIDOV ON, SAITO S, et al. ING2 regulates the onset of replicative senescence by induction of p300-dependent p53 acetylation. Mol Cell Biol 2005; 25: 6639-6648. http://dx.doi.org/10.1128/ MCB.25.15.6639-6648.2005

[17] GOZANI O, KARUMAN P, JONES DR, IVANOV D, CHA J, et al. The PHD finger of the chromatin-associated protein ING2 functions as a nuclear phosphoinositide receptor. Cell 2003; 114: 99-111. http://dx.doi.org/10.1016/S0092-8674(03)00480-X

[18] WANG Y, WANG J, LI G. Leucine zipper-like domain is required for tumor suppressor ING2-mediated nucleotide excision repair and apoptosis. Febs Lett 2006; 580: 3787-3793. http://dx.doi.org/10.1016/j.febslet.2006.05.065

[19] UNOKI M, KUMAMOTO K, HARRIS CC. ING proteins as potential anticancer drug targets. Curr Drug Targets 2009; 10: 442-454. http://dx.doi.org/10.2174/138945009788185059

[20] GUNDUZ M, GUNDUZ E, RIVERA RS, NAGATSUKA H. The inhibitor of growth (ING) gene family: potential role in cancer therapy. Curr Cancer Drug Targets 2008; 8: 275-284. http://dx.doi.org/10.2174/156800908784533454

[21] KAMEYAMA K, HUANG CL, LIU D, MASUYA D, NAKASHIMA T, et al. Reduced ING1b gene expression plays an important role in carcinogenesis of non-small cell lung cancer patients. Clin Cancer Res 2003; 9: 4926-4934.

[22] KUMAMOTO K, FUJITA K, KUROTANI R, SAITO M, UNOKI M, et al. ING2 is upregulated in colon cancer and increases invasion by enhanced MMP13 expression. Int J Cancer 2009; 125: 1306-1315. http://dx.doi.org/10.1002/ijc.24437

[23] SOLIMAN MA, RIABOWOL K. After a decade of studyING, a PHD for a versatile family of proteins. Trends Biochem Sci 2007; 32: 509-519. http://dx.doi.org/10.1016/ j.tibs.2007.08.006

[24] SARKER KP, KATAOKA H, CHAN A, NETHERTON SJ, POT I, et al. ING2 as a novel mediator of transforming growth factor-beta-dependent responses in epithelial cells. J Biol Chem 2008; 283: 13269-13279. http://dx.doi.org/10.1074/jbc. M708834200

[25] SIRONI E, CERRI A, TOMASINI D, SIRCHIA SM, PORTA $\mathrm{G}$, et al. Loss of heterozygosity on chromosome 4q32-35 in sporadic basal cell carcinomas: evidence for the involvement of p33ING2/ING1L and SAP30 genes. J Cutan Pathol 2004; 31 : 318-322. http://dx.doi.org/10.1111/j.0303-6987.2004.0187.x
[26] BORKOSKY SS, GUNDUZ M, NAGATSUKA H, BEDER LB, GUNDUZ E, et al. Frequent deletion of ING2 locus at $4 \mathrm{q} 35.1$ associates with advanced tumor stage in head and neck squamous cell carcinoma. J Cancer Res Clin Oncol 2009; 135: 703-713. http://dx.doi.org/10.1007/s00432-008-0507-y

[27] OKANO T, GEMMA A, HOSOYA Y, HOSOMI Y, NARA M, et al. Alterations in novel candidate tumor suppressor genes, ING1 and ING2 in human lung cancer. Oncol Rep 2006; 15: 545-549.

[28] YTHIER D, LARRIEU D, BINET R, BINDA O, BRAMBILLA $\mathrm{C}$, et al. Sumoylation of ING2 regulates the transcription mediated by Sin3A. Oncogene 2010; 29: 5946-5956. http://dx.doi. org/10.1038/onc.2010.325

[29] LU F, DAI DL, MARTINKA M, HO V, LI G. Nuclear ING2 expression is reduced in human cutaneous melanomas. Br J Cancer 2006; 95: 80-86. http://dx.doi.org/10.1038/ sj.bjc. 6603205

[30] ZHANG HK, PAN K, WANG H, WENG DS, SONG HF, et al. Decreased expression of ING2 gene and its clinicopathological significance in hepatocellular carcinoma. Cancer Lett 2008; 261: 183-192. http://dx.doi.org/10.1016/ j.canlet.2007.11.019

[31] LARRIEU D, YTHIER D, BRAMBILLA C, PEDEUX R. ING2 controls the G1 to S-phase transition by regulating p21 expression. Cell Cycle 2010; 9: 3984-3990. http://dx.doi. org/10.4161/cc.9.19.13208

[32] LI G, PICHE B. ING2 in cell cycle regulation. Cell Cycle 2010; 9: 3846. http://dx.doi.org/10.4161/cc.9.19.13382

[33] SAITO M, KUMAMOTO K, ROBLES AI, HORIKAWA I, FURUSATO B, et al. Targeted disruption of Ing2 results in defective spermatogenesis and development of soft-tissue sarcomas. PLoS One 2010; 5: e15541. http://dx.doi. org/10.1371/journal.pone.0015541

[34] YTHIER D, BRAMBILLA E, BINET R, NISSOU D, VESIN A, et al. Expression of candidate tumor suppressor gene ING2 is lost in non-small cell lung carcinoma. Lung Cancer-J Iaslc 2010; 69: 180-186. http://dx.doi.org/10.1016/ j.lungcan.2009.11.006

[35] SAKAKURA C, HAGIWARA A, TANIGUCHI H, YAMAGUCHI T, YAMAGISHI H, et al. Chromosomal aberrations in human hepatocellular carcinomas associated with hepatitis $\mathrm{C}$ virus infection detected by comparative genomic hybridization. Br J Cancer 1999; 80: 2034-2039. http://dx.doi. org/10.1038/sj.bjc.6690638

[36] VIEYRA D, SENGER DL, TOYAMA T, MUZIK H, BRASHER $\mathrm{PM}$, et al. Altered subcellular localization and low frequency of mutations of ING1 in human brain tumors. Clin Cancer Res 2003; 9: 5952-5961.

[37] YANG HY, LIU HL, TIAN LT, SONG RP, SONG X, et al. Expression and prognostic value of ING3 in human primary hepatocellular carcinoma. Exp Biol Med (Maywood) 2012; 237: 352-361. http://dx.doi.org/10.1258/ebm.2011.011346

[38] YTHIER D, LARRIEU D, BRAMBILLA C, BRAMBILLA E, PEDEUX R. The new tumor suppressor genes ING: genomic structure and status in cancer. Int J Cancer 2008; 123: 1483-1490. http://dx.doi.org/10.1002/ijc.23790 